\title{
BMJ Open Factors influencing COVID-19 vaccination uptake among community members in Hong Kong: a cross- sectional online survey
}

\author{
Cho Lee Wong (D) , Alice W Y Leung (D) , Oscar Man Hon Chung, \\ Wai Tong Chien
}

To cite: Wong CL, Leung AWY, Chung $\mathrm{OMH}$, et al. Factors influencing COVID-19 vaccination uptake among community members in Hong Kong: a cross-sectional online survey. BMJ Open 2022;12:e058416. doi:10.1136/ bmjopen-2021-058416

- Prepublication history and additional supplemental material for this paper are available online. To view these files, please visit the journal online (http://dx.doi.org/10.1136/ bmjopen-2021-058416).

Received 15 0ctober 2021 Accepted 09 February 2022

Check for updates

(c) Author(s) (or their employer(s)) 2022. Re-use permitted under CC BY-NC. No commercial re-use. See rights and permissions. Published by BMJ.

The Nethersole School of Nursing, Faculty of Medicine, The Chinese University of Hong Kong, Hong Kong, China

Correspondence to Professor Wai Tong Chien; wtchien@cuhk.edu.hk

\section{ABSTRACT}

Objective Vaccination is recognised as the most effective approach to contain the spread of the COVID-19 pandemic in the long run. However, the global vaccination uptake is still suboptimal. Although a considerable number of studies have focused on factors influencing intention or acceptance of COVID-19 vaccination, few explore the factors that affect actual vaccination uptake. This study aimed to explore the factors influencing COVID-19 vaccination uptake among the general public in a developed country.

Design A cross-sectional online survey was conducted between June and August 2021.

Setting and participants Community members in Hong Kong were recruited through convenient and snowball sampling to complete an anonymous online survey. Outcome measures The outcomes of this study included participants' sociodemographic characteristics, vaccination status and perceived impact of COVID-19, and their attitudes towards COVID-19.

Results A total of 358 valid questionnaires were received. The results showed that $50.8 \%$ of the participants received two doses of the vaccine. Multivariable logistic regression analysis suggested that the participants' vaccination uptake was associated with their jobs affected by COVID-19, had an income source, perceived good/ excellent physical health status, perceived COVID-19 exposure, perceived good/excellent knowledge of COVID-19, learnt about the vaccine from printed materials and perceived that their family members were at risk of contracting COVID-19.

Conclusions This is one of the first few cross-sectional studies that explored factors associated with the actual vaccination uptake of the general public during the COVID-19 pandemic. The results can provide insights for formulating strategies to increase COVID-19 vaccination rates in developed countries.

\section{INTRODUCTION}

Shortly after the COVID-19 outbreak in China around December 2019, the infection quickly spread across the globe and caused disturbances in many aspects of life. As of 31 August 2021, more than 217 million infected cases and more than 4.5 million deaths have
Strengths and limitations of this study

- This study explored factors associated with the actual vaccination uptake among Hong Kong community members during the COVID-19 pandemic, including sociodemographics, perceived impact of COVID-19 and attitudes towards COVID-19.

- This study adopted a cross-sectional design so that the causality cannot be ascertained.

- This non-random sample was over-represented by female, highly educated and younger adults.

- The use of self-report questionnaires might also be subject to social desirability bias and inaccurate understanding and responses to the questionnaire.

been recorded worldwide. ${ }^{1}$ At the same time, Hong Kong has experienced four waves of COVID-19 infection, with confirmed cases and deaths stagnating at around 12000 and 200, respectively. ${ }^{2}$

To contain the spread of the pandemic, governments around the world have adopted measures such as social distancing and border control. These measures imposed many restrictions on individuals and caused heavy health and economic losses. ${ }^{34}$ Alternatively, achieving herd immunity against COVID-19 through vaccinations is considered the most effective means to contain the spread of the pandemic in the long run. ${ }^{56}$

As of 31 August 2021, only 27.1\% of the global population has been fully vaccinated. ${ }^{1}$ The current vaccination rate in most countries is far below the target group herd immunity thresholds $(15.3 \%-77.1 \%){ }^{7}$ Due to the ample supply of vaccines in high-income and upper-middle-income countries, the suboptimal COVID-19 vaccination rate in most countries indicate that vaccine hesitancy is prevalent. The WHO defines vaccine hesitancy as 'the delay in acceptance or refusal of vaccination despite the availability of 
vaccination services', ${ }^{8}$ and listed it as one of the $10 \mathrm{top} /$ major threats to global health in 2019. ${ }^{9}$

In Hong Kong, the government has launched a territory-wide vaccination programme on 26 February 2021, providing all Hong Kong residents with free CoronaVac (Sinovac) inactivated vaccine and the Comirnaty (BioNTech) mRNA vaccine. ${ }^{10}$ The vaccination progress had been slow until a sudden surge was observed in mid-June (7-day moving average of total doses administered $>40000^{10}$ ), which might be attributable to the government's 'Early Vaccination for All' campaign, which features the facilitation and reward strategies for vaccinated people (eg, vaccination leave and relaxation of social distancing). ${ }^{11}$ In addition, the business sector also held some lucky draws (for example, the first prize of a HK $\$ 7$ million flat, HK\$1 million) to boost the COVID-19 vaccination rate. However, the current vaccination rate in Hong Kong (around 50\% at the end of August) is still far from reaching the target of at least $70 \%$ of the eligible population. ${ }^{12}$ The suboptimal vaccination rates call for more effective strategies to overcome barriers, not just merely provide incentives.

Emerging epidemiological evidence suggests a broad array of factors that affect the intention to vaccinate against COVID-19 among the general public, including sociodemographic factors such as age ${ }^{13-15}$ and employment status ${ }^{1314}$; disease-specific factors such as risk perception $^{15-17}$ and COVID-19 information exposure ${ }^{14-18}$; and vaccine-specific factors such as confidence in efficacy and safety $^{13-15} 1719$ and vaccination attitudes. ${ }^{1520} 21$ However, the major factors influencing actual vaccine uptake have seldom been explored. A recent cross-sectional study on 1037 older Germans suggested that general health condition, the presence of chronic conditions, perceptions of infection, the severity of potential long-term effects, the efficacy of vaccines, the benefits of vaccination, the negative side effects of vaccines and the general impediments to vaccination were the determinants of actual vaccination. ${ }^{17}$

After the launch of the territory-wide vaccination programme in Hong Kong, a few population-based surveys have explored the factors that influence vaccination uptake. These surveys reported a vaccine hesitancy rate of $27.6 \%-44.6 \% .{ }^{22}{ }^{23}$ The major reasons for vaccine hesitancy included physically unfit for vaccination due to medical reasons ${ }^{22}$ and worried about serious side effects of vaccines. ${ }^{22} 23$ In a telephone survey on Hong Kong citizens' attitudes and opinions on vaccination, respondents who had received the vaccine had a significantly higher rating on the government's antiepidemic efforts than those who had not been vaccinated. ${ }^{23}$

Existing studies on vaccination intentions are largely conducted before the commencement of the worldwide mass vaccination programme. With the further advancement of vaccine technology and the rapid emergence of COVID-19 variants, the factors that predict the actual vaccine uptake have yet to be determined. In this context, there is an urgent need to conduct more studies to investigate the factors related to actual vaccination uptake to inform the current and future measures to promote vaccination uptake in Hong Kong and other developed countries. Therefore, this study aimed to explore the factors that affect COVID-19 vaccine uptake among general populations in Hong Kong.

\section{METHODS}

\section{Study design}

This study adopted a cross-sectional design using an online survey.

\section{Setting and sample}

Participants were recruited online from June to August 2021. Eligible participants were community members (1) aged 18 or above; (2) able to understand the instructions and items of the questionnaire in either Chinese or English and (3) given written consent (by answering 'yes' on the first page of the survey). Participants who selfdisclosed that they had major depressive disorder, cognitive impairment, or illiteracy were excluded.

The sample size was determined to allow adequate precision to estimate the COVID-19 vaccination rate. By using the power analysis software, PASS V.16.0 (NCSS, Kaysville, USA), it was estimated that a sample size of $\mathrm{n}=340$ participants would allow the study to estimate the uptake rate with a margin of error of at most $\pm 5 \%$ at a level of significance of 0.05 based on an anticipated uptake rate of around one-third.

For the online surveys, an online survey portal was created using SurveyMonkey, a secure cloud-based online survey platform. A brief study description, consent form and questionnaires were included in the online survey portal. Participants were invited to participate in the study through the social messaging mobile application WhatsApp. A link was rolled out through various WhatsApp groups from staff working in a local university. Participants were recruited through convenient and snowball sampling. All respondents were asked to forward the link to their family and friends. Potential participants responded to the invitation by clicking a link that directed them to the online survey portal. They were asked to click the 'yes' button on the first page of study information and instructions to indicate their consent to participate. After consented, they would complete a set of self-developed questionnaire online, lasting about $8-10 \mathrm{~min}$. The study protocol is shown in online supplemental file 1.

\section{Survey instrument}

The research team developed a set of questionnaires comprising three sections with references to previous studies of similar topics, ${ }^{14} 1624$ and the current recommendations and guidelines from health authorities. The primary version was prepared in English and translated into Cantonese using standard translating procedures. The translated version was then reviewed by a panel of experts to ensure semantic and content equivalence. 
A convenience sample of 20 community members of different ages was then invited to comment on the clarity of the items and whether they had difficulty in answer the questions before actual use. All of them reported they had no difficulty in understanding the questions. The questionnaire (online supplemental file 2) consisted of three sections:

1. Participants' sociodemographic characteristics, health conditions and lifestyle characteristics, including age, gender, place of birth, living status, marital status, highest educational qualification, current employment condition, comorbidities, smoking and alcohol drinking status, perceived physical and mental health status.

2. Vaccination status and perceived impact of COVID-19: uptake of COVID-19 vaccination (yes/no), reasons for/against vaccination (an open-ended question), the impact of COVID-19 on the financial situation, contact with known/suspected cases of COVID-19, perceived COVID-19 exposure, perceived knowledge of COVID-19 and COVID-19 vaccines, sources of information about COVID-19 and COVID-19 vaccines, healthcare service used to overcome COVID-19 related stress in the past 6 months.

3. Attitudes towards COVID-19: a 10-item questionnaire developed by the research team ${ }^{.24}$ The questionnaire comprises two subscales: perceived risk of COVID-19 (seven items) and perceived self-efficacy in controlling COVID-19 (three items). Each item was rated on a 5-point Likert scale (from 1='strongly disagree' to $5=$ 'strongly agree'. The internal consistency of the scale in this study was satisfactory (Cronbach's alpha=0.71).

\section{Statistical analysis}

The participant's characteristics, including sociodemographics, health conditions and lifestyle characteristics, and experience or perceptions related to COVID-19, perceived risk of COVID-19 and perceived self-efficacy in controlling COVID-19 were categorised and presented using frequency and percentage. These characteristics were compared between the participants who had been vaccinated (at least one dose) and those who had not, using Pearson's $\chi^{2}$ test. Those characteristics with $\mathrm{p}<0.25$ in univariate analyses were selected as candidate independent variables for a backward multivariable logistic regression analysis to delineate factors significantly and independently associated with their vaccination status. All statistical analyses were performed using IBM SPSS V.25.0 (IBM), and the level of significance was set at 0.05 (two sided).

\section{Patient and public involvement}

Patients and/or the public were not involved in the design, or conduct, or reporting, or dissemination plans of this research.
RESULTS

\section{Sample characteristics}

A total of 384 community members consented online and participated in the study. Twenty-six respondents were excluded from the analyses due to having missing data on more than $30 \%$ of the questionnaire items. The remaining participants completed all the items in the questionnaire. Hence, the final sample were 358 participants (ie, completion rate $=93.2 \%$ ). The mean age of the participants was $38.27(\mathrm{SD}=14.79)$, and $69.0 \%$ were female. Table 1 shows a summary of the socio-demographic characteristics, health conditions and lifestyle characteristics of the participants.

\section{Uptake of COVID-19 vaccination and reasons}

Overall, $67.8 \%(243 / 358)$ of the participants had received at least one dose of the COVID-19 vaccine and, among those vaccinated, $74.9 \%$ (182/243) had received two doses. Table 2 summarises the main reasons for vaccination, and the most commonly reported reasons were 'desire to protect self' $(70.0 \%)$ and 'desire to protect friends/family' (60.9\%). Over half of those not vaccinated $(51.4 \%)$ reported low intention (scored $0-3)$ to get vaccinated in the following 15 days. The most commonly cited reason for their hesitancy was their 'concern about the side effects and safety of the vaccine' (60.0\%), followed by a 'plan to wait and see if it is safe and may get it later' $(51.3 \%)$ (see table 2$)$.

\section{Other information concerning COVID-19 impacts and vaccinations}

Table 3 summarises the information concerning COVID-19 impacts and vaccinations. The majority of them $(78.2 \%)$ perceived the pandemic did not impact their financial situation. Only $7 \%$ of them had known or suspected contact(s) with COVID-19 cases, but nearly one-fifth $(22.6 \%)$ perceived they had been exposed to COVID-19, and $16.4 \%$ had a consultation due to COVID-19 related stress in the last 6 months. About onethird of the participants perceived that they had good or excellent knowledge about COVID-19 (36.6\%) and COVID-19 vaccines $(34.3 \%)$; of which, their sources of knowledge were from the internet $(70.7 \%$ and $69.8 \%$, respectively) and television $(69.8 \%$ and $62.8 \%$, respectively). The figures of source of knowledge and comparison of information sources on COVID-19 by COVID-19 vaccination and COVID-19 vaccine by COVID-19 vaccination are shown in online supplemental file 3.

\section{Risk perception and self-efficacy}

The majority of the participants agreed that COVID-19 was a serious disease $(73.8 \%)$; their health would be severely affected if they got infected with COVID-19 (65.7\%), and they were fearful that they would become infected $(58.4 \%)$ or be quarantined $(58.4 \%)$. However, only a few $(7.5 \%)$ perceived that they or their family members were at risk of COVID-19 infection. More than half of them were confident that they could protect themselves against 
Table 1 Characteristics of the study sample ( $N=358)$

\begin{tabular}{|c|c|c|}
\hline \multirow[b]{2}{*}{ All (N=358) } & \multicolumn{2}{|c|}{ Vaccinated against COVID-19 } \\
\hline & No $(n=115)$ & Yes $(n=243)$ \\
\hline n (\%) & n (\%) & n (\%) \\
\hline
\end{tabular}

\section{Sociodemographic characteristics}

Age (years)

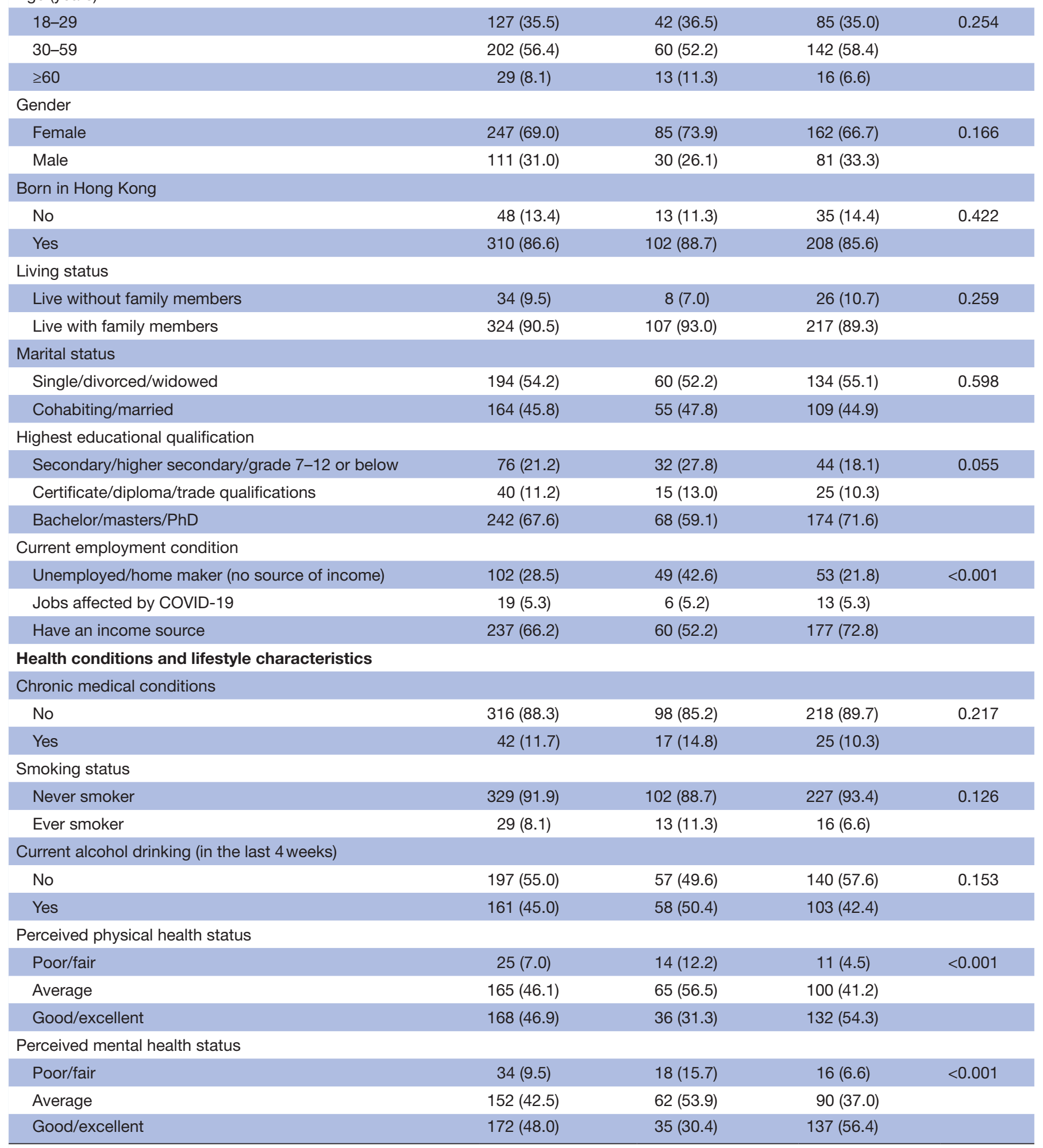

Data are presented as frequency (\%).

${ }^{*}$ All the $p$ values were computed based on the Pearson $\chi^{2}$ test. 
Table 2 Reasons for vaccine uptake and hesitancy

\begin{tabular}{|c|c|}
\hline $\begin{array}{l}\text { Reasons for getting vaccinated against } \\
\text { COVID-19* }(\mathrm{N}=243)\end{array}$ & n (\%) \\
\hline Desire to protect self & $170(70.0)$ \\
\hline Desire to protect friends/family & $148(60.9)$ \\
\hline Desire to help flatten the curve of disease & $123(50.6)$ \\
\hline Desire to travel aboard & $101(41.6)$ \\
\hline Compulsory in the workplace & $57(23.5)$ \\
\hline $\begin{array}{l}\text { Others (Worry about availability of } \\
\text { vaccines in the future, study-related } \\
\text { requirements, visit elderly homes) }\end{array}$ & $12(4.9)$ \\
\hline $\begin{array}{l}\text { Reasons for not getting vaccinated } \\
\text { against COVID-19* }(\mathrm{N}=115)\end{array}$ & n (\%) \\
\hline $\begin{array}{l}\text { Concern about the side effects and safety } \\
\text { of the vaccine }\end{array}$ & $69(60.0)$ \\
\hline $\begin{array}{l}\text { Plan to wait and see if it is safe and may } \\
\text { get it later }\end{array}$ & 59 (51.3) \\
\hline $\begin{array}{l}\text { The vaccine is being developed too } \\
\text { quickly }\end{array}$ & $32(27.8)$ \\
\hline $\begin{array}{l}\text { Others (chronic disease, pregnant, not } \\
\text { understanding self-health, after surgery, } \\
\text { allergy, planning) }\end{array}$ & $16(4.5)$ \\
\hline The vaccine will not work & $11(9.6)$ \\
\hline Don't like needles & $11(9.6)$ \\
\hline $\begin{array}{l}\text { The doctor did not recommend me for } \\
\text { COVID-19 vaccination }\end{array}$ & $9(7.8)$ \\
\hline
\end{tabular}

*Multiple responses possible.

COVID-19 (64.8\%) and that the infection could finally be controlled in Hong Kong (55.7\%) (see table 4).

\section{Factors associated with uptake of COVID-19 vaccination}

From the bivariate analyses (tables 1,3 and 4), the uptake of COVID-19 vaccination was associated with current employment condition $(\mathrm{p}<0.001)$, perceived health status $(p<0.001)$, perceived mental health status $(p<0.001)$, contact with the known suspected case(s) of COVID-19 $(\mathrm{p}<0.017)$, perceived exposure to COVID-19 ( $\mathrm{p}=0.003)$, perceived knowledge of COVID-19 $(\mathrm{p}<0.001)$, perceived knowledge of COVID-19 vaccines $(\mathrm{p}<0.001)$, healthcare providers as a source of knowledge about COVID-19 $(\mathrm{p}=0.004)$, healthcare providers $(\mathrm{p}=0.017)$ and brochures, posters, and other printed materials $(\mathrm{p}=0.004)$ as sources of knowledge about COVID-19 vaccines, perception about family members being at risk of COVID-19 infection $(\mathrm{p}=0.032)$, and confidence in protecting themselves against COVID-19 $(\mathrm{p}=0.031)$.

The results from backward multivariable logistic regression analysis (see table 5) revealed that the participants whose jobs were affected by COVID-19 (OR 4.83, 95\% CI 1.18 to 19.76 ), had an income source (OR 2.10, 95\% CI 1.18 to 3.72), perceived good/excellent physical health status (OR 5.09, 95\% CI 1.17 to 22.08), perceived exposure to COVID-19 (OR 2.69, 95\% CI 1.28 to 5.65), perceived to have good/ excellent knowledge of COVID-19 (OR 2.65, 95\% CI 1.43 to 4.93), reported learning about COVID-19 vaccines from brochures, posters and other printed materials (OR 1.95, 95\% CI 1.05 to 3.63), and perceived their family was at risk of COVID-19 infection (OR 4.02, 95\% CI 1.08 to 14.87 ) were positively associated with vaccination uptake. Alternatively, those who reported learning about COVID-19 from the internet were less likely to receive a COVID-19 vaccine (OR $0.50,95 \%$ CI 0.26 to 0.98 ).

\section{DISCUSSION}

To our knowledge, this study is one of the few studies that explored the factors influencing actual vaccination uptake during the COVID-19 pandemic among community members in Hong Kong and worldwide. In our study, approximately $70 \%$ of the sample received at least one dose of the vaccine, which is higher than the officially announced vaccination uptake rate $(\sim 50 \%)^{10}$ and reported in two local cross-sectional studies during the same study period. ${ }^{22}{ }^{23}$ Despite the high vaccination uptake, half of the unvaccinated respondents indicated that the willingness to be vaccinated in the next 15 days was low, revealing a considerable level of vaccine hesitancy in our sample. This finding echoed with other local public health studies ${ }^{22} 23$ in which the main concerns reported by unvaccinated people were the side effects and safety of available vaccines. This was also a well recognised or commonly cited reason for vaccine hesitancy reported consistently in different countries. ${ }^{13-15} 21-232526$ This implies that further efforts in public education should focus on conveying scientific evidence and knowledge about the efficacy and safety of various available vaccines to enhance their evidence-based decision making on vaccination.

Among various sociodemographic factors, employment condition was found to be an independent determinant of vaccination uptake. Specifically, those who were unemployed or homemaker were less likely to be vaccinated than those who were working or who had their employment affected by the COVID-19 pandemic. As an increasing number of employers adopted vaccination instead of regular testing approaches proposed by the (local) government, unvaccinated employees would require to undergo self-financed COVID-19 testing every 2weeks. ${ }^{27}$ Such testing requirements may encourage more employees or job seekers to get vaccinated. Similarly, a recent international study found that unemployed people but not seek a job reported a lower intention to be vaccinated. ${ }^{13}$ This suggests that vaccination campaigns may effectively highlight vaccination's financial or economic benefits to the working population (such as resuming normal business conditions and more job opportunities). Nevertheless, efforts should also be made to promote the various benefits of vaccination to the nonworking population, such as a gradual return to normal life after achieving herd community. 
Table 3 Information concerning COVID-19 impacts and vaccinations

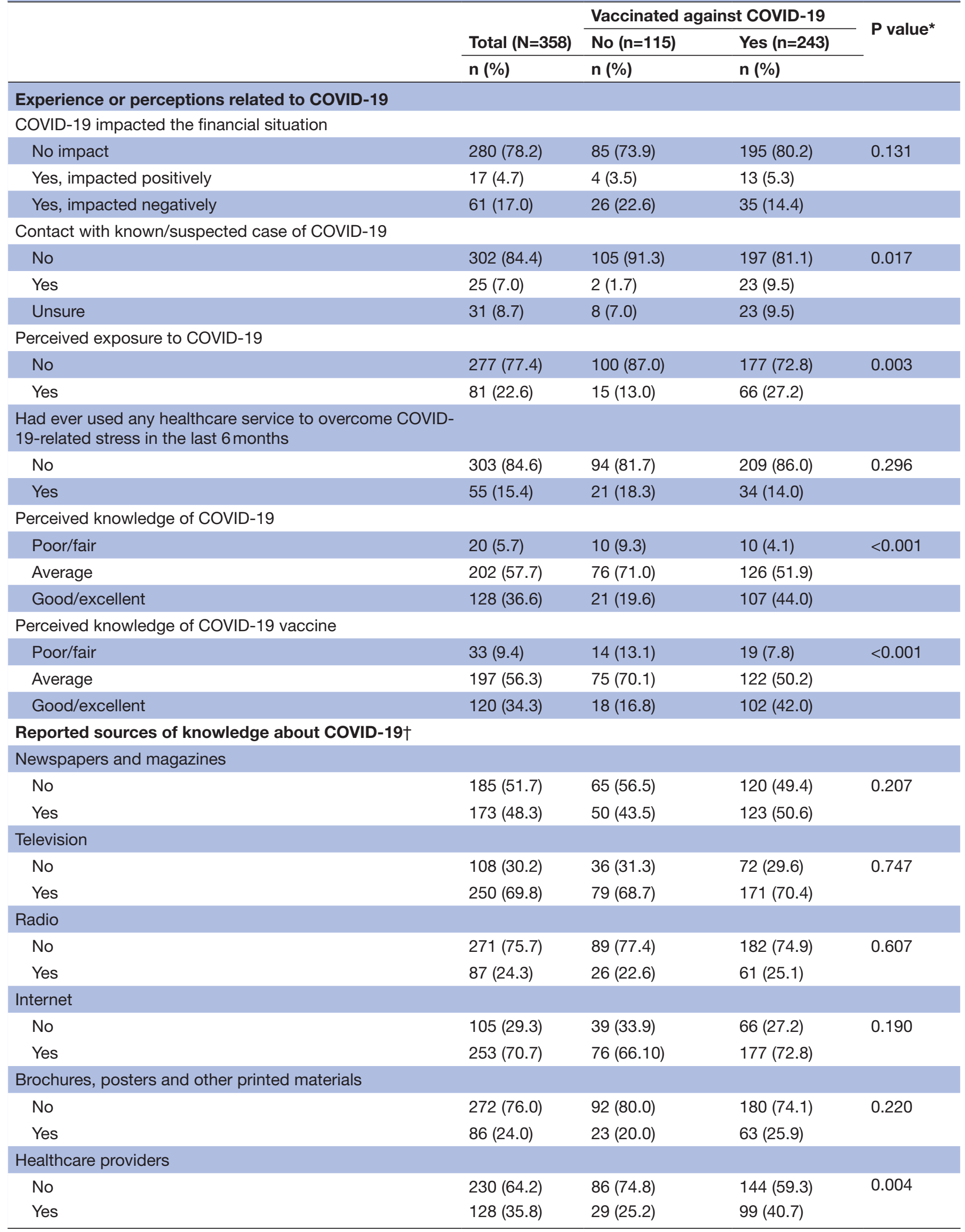


Table 3 Continued

\begin{tabular}{|c|c|c|c|c|}
\hline & & Vaccinated & th COVID-19 & D volu* \\
\hline & Total $(\mathrm{N}=358)$ & No $(n=115)$ & Yes $(n=243)$ & T value \\
\hline & n (\%) & n (\%) & n (\%) & \\
\hline Family & & & & \\
\hline No & $261(72.9)$ & $82(71.3)$ & $179(73.7)$ & 0.639 \\
\hline Yes & $97(27.1)$ & $33(28.7)$ & 64 (26.3) & \\
\hline Friends & & & & \\
\hline No & $231(64.5)$ & $71(61.7)$ & $160(65.8)$ & 0.448 \\
\hline Yes & 127 (35.5) & 44 (38.3) & $83(34.2)$ & \\
\hline $\begin{array}{l}\text { Report } \\
\text { vaccin }\end{array}$ & & & & \\
\hline Newsp & & & & \\
\hline No & $219(61.2)$ & 73 (63.5) & $146(60.1)$ & 0.538 \\
\hline Yes & 139 (38.8) & $42(36.5)$ & 97 (39.9) & \\
\hline TV & & & & \\
\hline No & $133(37.2)$ & 38 (33.0) & $95(39.1)$ & 0.269 \\
\hline Yes & 225 (62.8) & 77 (67.0) & 148 (60.9) & \\
\hline Radio & & & & \\
\hline No & $275(76.8)$ & $89(77.4)$ & $186(76.5)$ & 0.859 \\
\hline Yes & $83(23.2)$ & 26 (22.6) & 57 (23.5) & \\
\hline Interne & & & & \\
\hline No & 108 (30.2) & 39 (33.9) & 69 (28.4) & 0.288 \\
\hline Yes & $250(69.8)$ & $76(66.1)$ & $174(71.6)$ & \\
\hline Brochu & & & & \\
\hline No & $250(69.8)$ & 90 (78.3) & $160(65.8)$ & 0.017 \\
\hline Yes & 108 (30.2) & 25 (21.7) & 83 (34.2) & \\
\hline Healthc & & & & \\
\hline No & $247(69.0)$ & 91 (79.1) & $156(64.2)$ & 0.004 \\
\hline Yes & $111(31.0)$ & 24 (20.9) & 87 (35.8) & \\
\hline Family & & & & \\
\hline No & 279 (77.9) & 88 (76.5) & $191(78.6)$ & 0.658 \\
\hline Yes & $79(22.1)$ & 27 (23.5) & $52(21.4)$ & \\
\hline Friends & & & & \\
\hline No & $232(64.8)$ & 70 (60.9) & $162(66.7)$ & 0.284 \\
\hline Yes & $126(35.2)$ & 45 (39.1) & 81 (33.3) & \\
\hline
\end{tabular}

Data are presented as frequency (\%).

${ }^{*}$ All the $p$ values were computed based on the Pearson $\chi^{2}$ test.

†Multiple responses possible.

This study identified several knowledge-related factors influencing vaccination uptake. In the bivariate analysis, both perceived knowledge of COVID-19 and its vaccines were associated with vaccination uptake, but only perceived knowledge of COVID-19 remained a significant factor in the multivariable model. Likewise, a recent British population-based survey showed that the perception of sufficient information/knowledge about COVID-19 and the vaccine was positively correlated with the intention to vaccinate. ${ }^{15}$ Regarding information sources, our study found that those who learnt about the COVID-19 vaccines through brochures, posters, and other printed materials were more likely to receive the vaccine. Interestingly, those who reported that they learnt from the internet were less likely to be vaccinated. One possible explanation for these findings is that printed materials are more likely to be produced by authoritative bodies (eg, Department of Health ${ }^{28}$ based on the latest 
Table 4 Risk perception and self-efficacy

\begin{tabular}{|c|c|c|c|c|}
\hline \multirow[b]{2}{*}{ Item } & \multirow[b]{2}{*}{$\begin{array}{l}\text { All }(\mathrm{N}=332) \\
\mathrm{n}(\%)\end{array}$} & \multicolumn{2}{|c|}{ Vaccinated against COVID-19 } & \multirow[b]{2}{*}{$P$ value* } \\
\hline & & $\begin{array}{l}\text { No }(n=103) \\
n(\%)\end{array}$ & $\begin{array}{l}\text { Yes }(n=229) \\
n(\%)\end{array}$ & \\
\hline \multicolumn{5}{|l|}{ Perceived risk of COVID-19 } \\
\hline 1. I think COVID-19 is a serious disease & & & & 0.059 \\
\hline Strongly disagree/disagree/uncertain & 87 (26.2) & $34(33.0)$ & $53(23.1)$ & \\
\hline Agree/strongly agree & $245(73.8)$ & $69(67.0)$ & $176(76.9)$ & \\
\hline \multicolumn{5}{|l|}{ 2. I think I will get infected with COVID-19 } \\
\hline Strongly disagree/disagree/uncertain & $307(92.5)$ & $99(96.1)$ & $208(91.8)$ & 0.091 \\
\hline Agree/strongly agree & $25(7.5)$ & $4(3.9)$ & $21(9.2)$ & \\
\hline 3. I think my family will get infected with COVID-19 & & & & 0.032 \\
\hline Strongly disagree/disagree/uncertain & $307(92.5)$ & $100(97.1)$ & $207(91.4)$ & \\
\hline Agree/strongly agree & $25(7.5)$ & $3(2.9)$ & $22(9.6)$ & \\
\hline \multicolumn{5}{|l|}{ 4. I am fear of getting infected with COVID-19 } \\
\hline Strongly disagree/disagree/uncertain & $138(41.6)$ & $42(40.8)$ & $96(41.9)$ & 0.845 \\
\hline Agree/strongly agree & $194(58.4)$ & $61(59.2)$ & $133(58.1)$ & \\
\hline \multicolumn{5}{|l|}{ 5. I am fearful of getting quarantined if I get infected } \\
\hline Strongly disagree/disagree/uncertain & $138(41.6)$ & $43(41.7)$ & $95(41.5)$ & 0.964 \\
\hline Agree/strongly agree & $194(58.4)$ & $60(58.3)$ & $134(58.5)$ & \\
\hline \multicolumn{5}{|l|}{$\begin{array}{l}\text { 6. My health will be severely affected if I get infected with } \\
\text { COVID-19 }\end{array}$} \\
\hline Strongly disagree/disagree/uncertain & $114(34.3)$ & 39 (37.9) & 75 (32.8) & 0.364 \\
\hline Agree/strongly agree & $218(65.7)$ & $64(62.1)$ & $154(67.2)$ & \\
\hline
\end{tabular}

7. I will not go to the hospital even if I get sick because of the risk of getting infected with COVID-19

$\begin{array}{lrrrr}\text { Strongly disagree/disagree/uncertain } & 290(87.3) & 88(85.4) & 202(88.2) & 0.482 \\ \text { Agree/strongly agree } & 42(12.7) & 15(14.6) & 27(11.8) & \end{array}$

Perceived self-efficacy in controlling COVID-19

1. I believe I can protect myself against COVID-19

Strongly disagree/disagree/uncertain

$117(35.2)$

$45(43.7)$

$72(31.4)$

0.031

Agree/strongly agree

$215(64.8)$

$58(56.3)$

$157(68.6)$

2. I believe COVID-19 can finally be successfully controlled

Strongly disagree/disagree/uncertain

Agree/strongly agree

$147(44.3)$

$51(49.5)$

96 (41.9)

0.198

3. I have confidence that Hong Kong can win the battle against COVID-19

\begin{tabular}{lllrl} 
Strongly disagree/disagree/uncertain & $142(42.8)$ & $43(41.7)$ & $99(43.2)$ & 0.800 \\
Agree/strongly agree & $190(57.2)$ & $60(58.3)$ & $130(56.8)$ & \\
\hline
\end{tabular}

Data are presented as frequency (\%).

${ }^{*}$ All the $p$ values were computed based on the Pearson $\chi^{2}$ test.

scientific evidence. At the same time, the internet is often fueled by the spread of inaccurate information (ie, an infodemic in which health information was mixed with fear, speculation and rumour, amplified swiftly worldwide by technologies such as the internet) ${ }^{29}$; whereas, higher news consumption through social media was associated with lower levels of knowledge and more fake news belief. ${ }^{30}$ Previous study also revealed that fake news led healthcare professionals to get information from accurate and reliable source. ${ }^{31}$ In this regard, a recent randomised controlled trial in the UK and the USA suggested that exposure to online misinformation can reduce the public's intention to vaccinate. ${ }^{18}$

In line with the finding that protecting friends and family is the major reason for vaccination, we found that individuals who perceived their family members were 
Table 5 Factors associated with the uptake of COVID-19 vaccination

\begin{tabular}{lll}
\hline Factors retained in backward logistic regression analysis* & OR (95\% Cl) & P value \\
\hline Sociodemographic characteristics & & \\
Current employment condition & 1 & 0.029 \\
Unemployed/home maker (no source of income) (ref) & 4.83 (1.18 to 19.76) & 0.011 \\
Jobs affected by COVID-19 & 2.10 (1.18 to 3.72) &
\end{tabular}

\section{Health conditions and lifestyle characteristics}

Perceived physical health status

Poor/fair (ref)

$\begin{array}{llr}\text { Average } & 3.17(0.80 \text { to } 12.63) & 0.101 \\ \text { Good/excellent } & 5.09(1.17 \text { to } 22.08) & 0.030\end{array}$

Perceived mental health status

Poor/fair (ref) 1

$\begin{array}{lll}\text { Average } & 1.47(0.49 \text { to } 4.38) & 0.490 \\ \text { Good/excellent } & 3.23 \text { (0.99 to } 10.53) & 0.052\end{array}$

\section{Experience or perceptions related to COVID-19}

Perceived exposure to COVID-19

\begin{tabular}{llc} 
No (ref) & 1 & 0.009 \\
\hline Yes & 2.69 (1.28 to 5.65) & 0.875 \\
\hline $\begin{array}{l}\text { Perceived knowledge of COVID-19 } \\
\text { Poor/fair }\end{array}$ & $1.12(0.28$ to 4.53$)$ & 0.002 \\
Average (ref) & 1 & 2.65 (1.43 to 4.93) \\
\hline Good/excellent & &
\end{tabular}

Reported internet as a source of knowledge about COVID-19

\begin{tabular}{lll} 
No & 1 & 0.045 \\
\hline Yes & $0.50(0.26$ to 0.98$)$ & \\
$\begin{array}{l}\text { Reported brochures, posters and other printed materials as sources of } \\
\text { knowledge about COVID-19 vaccines }\end{array}$ & 1 & 0.035 \\
\hline No & 1.95 (1.05 to 3.63) \\
Yes & & \\
\hline Perceived risk of COVID-19 & & \\
\hline I think my family will get infected with COVID-19 & 1 \\
\hline Strongly disagree/disagree/uncertain & $4.02(1.08$ to 14.87) \\
\hline Agree/strongly agree & 0.037 \\
\hline
\end{tabular}

*Significant factors retained from backward multivariable logistic regression analysis using the variables as listed in tables 1,3 and 4 with $p<0.25$ in the univariate analysis as candidate independent variables. ref, reference category of the categorical independent variable.

at risk of contracting COVID-19 were more likely to be vaccinated than those who have not reported this perception. Similarly, several reports show that consideration of others, particularly family members, regarding the threat of COVID-19 affects vaccination intention. ${ }^{13151821}$ Taken together, these results suggest that vaccination promotion messages should emphasise the generous benefits of vaccination to significant others and society at large, for example, the effectiveness of vaccination in reducing the infection risk at individual and collective levels. ${ }^{32}$
In this study, people's perceived COVID-19 exposure independently predicted their vaccination uptake. To our knowledge, this factor has not been reported as a predictor of vaccination intention or acceptance in previous studies. It can be speculated that those who perceive that they have not been exposed to the COVID-19 may not feel the urgency of vaccination, leading to vaccine hesitancy.

Notably, the final regression model was perceived to have good/excellent physical health status was the strongest factor for vaccination uptake. Likewise, this factor has 
been found to predict the intention of vaccination against COVID-19 among the general population in China. ${ }^{26}$ and actual vaccination uptake in a sample of the elderly population in Germany. ${ }^{17}$ It could be possible that people who perceive they were in poor health might be more worried about the vaccine's side effects, which would become a major obstacle to vaccination.

\section{Limitations}

This study has several limitations. First, this study adopted a cross-sectional design so that the causality between vaccination uptake and other variables could not be determined. Second, a non-random sample was used; and this might lead to selection bias and limit the generalisability of the findings. Third, the sample was found to be over-represented by female, highly educated and younger adults, so caution is needed to be taken when generalising the findings to the general population in Hong Kong. Finally, self-report questionnaires might also be subject to social desirability bias and inaccurate understanding and responses to the questionnaire, thereby reducing the reliability and validity of the findings.

\section{CONCLUSION}

This study is one of the few survey studies to explore the reasons and factors associated with the 'actual' vaccination uptake among the general population during the COVID-19. The results provide evidence and insights for formulating effective strategies to promote COVID-19 vaccination in Hong Kong and other developed countries.

AcknowledgmentsThe authors would like to thank all the participants in the study. Contributors CLW and WTC contributed to the study's conception and design. CLW was involved in gaining ethical approval. CLW involved in data collection. CLW, AWYL and OMHC analysed the data and wrote the first draft of the manuscript. All authors reviewed and edited the manuscript and approved the final version of the manuscript. CLW acted as guarantor of this study.

Funding This research did not receive any specific grant from funding agencies in the public, commercial, or not-for-profit sectors. The authors have not declared a specific grant for this research from any funding agency in the public, commercial or not-for-profit sectors.

Competing interests The authors declare that there is no conflict of interest.

\section{Patient consent for publication Not required.}

Ethics approval Ethical approval was obtained from the Survey and Behavioural Research Committee of The Chinese University of Hong Kong (SBRE-20-784). The Helsinki Declaration handled all study procedures involving human subjects. The participants were assured that their participation was voluntary, their rights to withdraw at any time were upheld, and their information was confidential.

Provenance and peer review Not commissioned; externally peer-reviewed.

Data availability statement Data are available on reasonable request. The anonymous data which form the basis for this study are available from the authors on reasonable request.

Supplemental material This content has been supplied by the author(s). It has not been vetted by BMJ Publishing Group Limited (BMJ) and may not have been peer-reviewed. Any opinions or recommendations discussed are solely those of the author(s) and are not endorsed by BMJ. BMJ disclaims all liability and responsibility arising from any reliance placed on the content. Where the content includes any translated material, BMJ does not warrant the accuracy and reliability of the translations (including but not limited to local regulations, clinical guidelines, terminology, drug names and drug dosages), and is not responsible for any error and/or omissions arising from translation and adaptation or otherwise.

Open access This is an open access article distributed in accordance with the Creative Commons Attribution Non Commercial (CC BY-NC 4.0) license, which permits others to distribute, remix, adapt, build upon this work non-commercially, and license their derivative works on different terms, provided the original work is properly cited, appropriate credit is given, any changes made indicated, and the use is non-commercial. See: http://creativecommons.org/licenses/by-nc/4.0/.

\section{ORCID iDs}

Cho Lee Wong http://orcid.org/0000-0001-6640-1323

Alice W Y Leung http://orcid.org/0000-0001-5217-0464

Wai Tong Chien http://orcid.org/0000-0001-5321-5791

\section{REFERENCES}

1 Coronavirus Resource Center. COVID-19 Dashboard, 2021. Available: https://coronavirus.jhu.edu/map.html [Accessed August 31 2021].

2 The Government of Hong Kong Special Administrative Region. Together,We Fight the Virus! 2021. Available: https://www. coronavirus.gov.hk/eng/index.html [Accessed August 31 2021].

3 Altig D, Baker S, Barrero JM, et al. Economic uncertainty before and during the COVID-19 pandemic. J Public Econ 2020;191:104274.

$4 \mathrm{Wu}$, Jia X, Shi H, et al. Prevalence of mental health problems during the COVID-19 pandemic: a systematic review and meta-analysis. $J$ Affect Disord 2021;281:91-8.

5 World Health Organization. COVID-19 advice for the public: getting vaccinated, 2021. Available: https://www.who.int/emergencies/ diseases/novel-coronavirus-2019/covid-19-vaccines/advice [Accessed August 31 2021].

6 Kwok KO, McNeil EB, Tsoi MTF, et al. Will achieving herd immunity be a road to success to end the COVID-19 pandemic? J Infect 2021;83:381-412.

7 Kwok KO, Lai F, Wei WI, et al. Herd immunity - estimating the level required to halt the COVID-19 epidemics in affected countries. $J$ Infect 2020;80:e32-3.

8 World Health Organization. Report of the SAGE Working group on vaccine Hesitancy, 2015. Available: http://www.who.int/ immunization/sage/meetings/2014/october/SAGE_working_group_ revised_report_vaccine_hesitancy.pdf [Accessed August 19 2021].

9 World Health Organization. Ten threats to global health in 2019, 2021 Available: https://www.who.int/news-room/spotlight/ten-threats-toglobal-health-in-2019 [Accessed August 19 2021].

10 The Government of Hong Kong Special Administrative Region. COVID-19 vaccination programme,, 2021. Available: https://www. covidvaccine.gov.hk/en/ [Accessed August 19 2021].

11 The Government of Hong Kong Special Administrative Region. Early Vaccination for All" campaign launched, 2021. Available: https:// www.info.gov.hk/gia/general/202105/31/P2021053100749.htm [Accessed August 19 2021].

12 news.gov.hk. Early vaccination urged, 2021. Available: https://www. news.gov.hk/eng/2021/07/20210718/20210718_131218_995.html [Accessed August 19 2021].

13 Burke PF, Masters D, Massey G. Enablers and barriers to COVID-19 vaccine uptake: an international study of perceptions and intentions. Vaccine 2021;39:5116-28.

14 Soares P, Rocha JV, Moniz M, et al. Factors associated with COVID-19 vaccine Hesitancy. Vaccines 2021;9:300.

15 Sherman SM, Smith LE, Sim J, et al. COVID-19 vaccination intention in the UK: results from the COVID-19 vaccination acceptability study (CoVAccS), a nationally representative cross-sectional survey. Hum Vaccin Immunother 2021;17:1612-21 https://doi.org/1080/21645515 2020.1846397

16 Viswanath K, Bekalu M, Dhawan D, et al. Individual and social determinants of COVID-19 vaccine uptake. BMC Public Health 2021;21:818.

17 Malesza M, Wittmann E. Acceptance and intake of COVID-19 vaccines among older Germans. J Clin Med 2021;10. doi:10.3390/ jcm10071388. [Epub ahead of print: 3003 2021].

18 Loomba S, de Figueiredo A, Piatek SJ, et al. Measuring the impact of COVID-19 vaccine misinformation on vaccination intent in the UK and USA. Nat Hum Behav 2021;5:337-48.

19 Wong MCS, Wong ELY, Huang J, et al. Acceptance of the COVID-19 vaccine based on the health belief model: a population-based survey in Hong Kong. Vaccine 2021;39:1148-56.

20 Kwok KO, Li KK, Tang A, et al. Psychobehavioral responses and likelihood of receiving COVID-19 vaccines during the pandemic, Hong Kong. Emerg Infect Dis 2021;27:1802-10. 
21 Yılmaz M, Sahin MK. Parents' willingness and attitudes concerning the COVID-19 vaccine: a cross-sectional study. Int J Clin Pract 2021;75:e14364.

22 The Chinese University of Hong Kong. Survey findings on views about COVID-19 released by Hong Kong Institute of Asia-Pacific studies at CUHK, 2021. Available: https://www.cpr.cuhk.edu.hk/en/ press/survey-findings-on-views-about-covid-19-released-by-hongkong-institute-of-asia-pacific-studies-at-cuhk-6/ [Accessed August 10 2021].

23 The Baptist University of Hong Kong. Vaccine Hesitancy study reports, 2021. Available: https://research.hkbu.edu.hk/highlightedprojects/overcoming-vaccine-hesitancy-in-hong-kong\#Reports [Accessed August 20 2021].

24 Wong CL, Chen J, Chow KM, et al. Knowledge, attitudes and practices towards COVID-19 amongst ethnic minorities in Hong Kong. Int J Environ Res Public Health 2020;17:7878.

25 Wang K, Wong EL-Y, Ho K-F, et al. Change of willingness to accept covid-19 vaccine and reasons of vaccine hesitancy of working people at different waves of local epidemic in Hong Kong, China: repeated cross-sectional surveys. Vaccines 2021;9:62.

26 Wang J, Zhang Y, Long S, et al. Non-EPI vaccine hesitancy among Chinese adults: a cross-sectional study. Vaccines 2021;9. doi:10.3390/vaccines9070772. [Epub ahead of print: 1007 2021].
27 The Government of Hong Kong Special Administrative Region. Government tightens eligibility criteria for free COVID-19 testing for targeted groups at community testing centres, 2021. Available: https://www.info.gov.hk/gia/general/202108/04/P2021080401030. htm [Accessed August 20 2021].

28 Hong Kong Department of Health. Health education materials, 2021. Available: https://www.chp.gov.hk/en/features/102745.html [Accessed August 31 2021].

29 Eysenbach G. Infodemiology: The epidemiology of (mis)information. Am J Med 2002;113:763-5.

30 Gerosa T, Gui M, Hargittai E. (Mis)informed during COVID-19: how education level and information sources contribute to knowledge gaps. Int J Commun 2021;15:2196-217.

31 Kaplan AK, Sahin MK, Parildar H, et al. The willingness to accept the COVID-19 vaccine and affecting factors among healthcare professionals: a cross-sectional study in turkey. Int J Clin Pract 2021;75:e14226.

32 Barello S, Palamenghi L, Graffigna G. Looking inside the 'black box' of vaccine hesitancy: unlocking the effect of psychological attitudes and beliefs on COVID-19 vaccine acceptance and implications for public health communication. Psychol Med 2021:1-2. 